\title{
Relaxation of the one child policy and trends in caesarean section rates and birth outcomes in China between 2012 and 2016: observational study of nearly seven million health facility births
}

\author{
Juan Liang, ${ }^{1}$ Yi Mu, ${ }^{1}$ Xiaohong Li, ${ }^{1}$ Wen Tang, ${ }^{1}$ Yanping Wang, ${ }^{2}$ Zheng Liu, ${ }^{1}$ Xiaona Huang, ${ }^{3}$ \\ Robert W Scherpbier, ${ }^{3}$ Sufang Guo, ${ }^{4}$ Mingrong Li, ${ }^{1}$ Li Dai, ${ }^{1}$ Kui Deng, ${ }^{1}$ Changfei Deng, ${ }^{1}$ Qi Li, ${ }^{1}$ \\ Leni Kang, ${ }^{2}$ Jun Zhu, ${ }^{1,5}$ Carine Ronsmans ${ }^{6,7}$
}

\begin{abstract}
For numbered affiliations see end of article.

Correspondence to:

C Ronsmans

Carine.Ronsmans@lshtm.ac.uk

Additional material is published online only. To view please visit the journal online.
\end{abstract}

Cite this as: $B M J$ 2018;360:k817 http://dx.doi.org/10.1136/bmj.k817

Accepted: 1 February 2018

\section{ABSTRACT}

OBJECTIVE

To examine how the relaxation of the one child policy and policies to reduce caesarean section rates might have affected trends over time in caesarean section rates and perinatal and pregnancy related mortality in China.

\section{DESIGN}

Observational study.

SETTING

China's National Maternal Near Miss Surveillance System (NMNMSS).

\section{PARTICIPANTS}

6838582 births at 28 completed weeks or more of gestation or birth weight $\geq 1000 \mathrm{~g}$ in 438 hospitals in the NMNMSS between 2012 and 2016.

\section{MAIN OUTCOME MEASURES}

Obstetric risk was defined using a modified Robson classification. The main outcome measures were changes in parity and age distributions and relative frequency of each Robson group, crude and adjusted trends over time in caesarean section rates within each risk category (using Poisson regression with a robust variance estimator), and trends in perinatal and pregnancy related mortality over time.

RESULTS

Caesarean section rates declined steadily between 2012 and 2016 (crude relative risk 0.91, 95\%

\section{WHAT IS ALREADY KNOWN ON THIS TOPIC}

Concerns have been raised over the health effects of increasing caesarean section rates throughout the world, but so far no country has managed to reverse this trend

Many studies have reported rising caesarean section rates in China, but few have included the period after the relaxation of the one child policy

The Chinese government has introduced several policies to reduce caesarean sections, but it is not known how this has affected caesarean section rates in various obstetric risk categories

\section{WHAT THIS STUDY ADDS}

The relaxation of the one child policy has resulted in an increased proportion of multiparous births, particularly with a uterine scar, and women giving birth at older ages

Caesarean section rates declined steadily between 2012 and 2016, particularly among nulliparous and multiparous births without a uterine scar, while rates remained unchanged in other risk categories

Perinatal mortality declined from 10.1 per 1000 births to 7.2 per 1000 births over the same period, and pregnancy related mortality did not change

confidence interval 0.89 to 0.93 ), reaching an overall hospital based rate of $41.1 \%$ in 2016 . The relaxation of the one child policy was associated with an increase in the proportion of multiparous births (from $34.1 \%$ in 2012 to $46.7 \%$ in 2016), and births in women with a uterine scar nearly doubled (from $9.8 \%$ to $17.7 \%$ of all births). Taking account of these changes, the decline in caesarean sections was amplified over time (adjusted relative risk 0.82, $95 \%$ confidence interval 0.81 to 0.84 ). Caesarean sections declined noticeably in nulliparous women $(0.75,0.73$ to 0.77$)$ but also declined in multiparous women without a uterine scar $(0.65,0.62$ to 0.77$)$. The decrease in caesarean section rates was most pronounced in hospitals with the highest rates in 2012, consistent with the government's policy of targeting hospitals with the highest rates. Perinatal mortality declined from 10.1 to 7.2 per 1000 births over the same period $(0.87,0.83$ to 0.91$)$, and there was no change in pregnancy related mortality over time.

\section{CONCLUSIONS}

China is the only country that has succeeded in reverting the rising trends in caesarean sections. China's success is remarkable given that the changes in obstetric risk associated with the relaxation of the one child policy would have led to an increase in the need for caesarean sections. China's experience suggests that change is possible when strategies are comprehensive and deal with the system level factors that underpin overuse as well as the various incentives at work during a clinical encounter.

\section{Introduction}

China has made remarkable progress in achieving the Millennium Development Goals, but its success has come at a cost. ${ }^{1-3}$ While nearly all women now deliver in hospital, many do so by caesarean section, and many caesarean sections are thought not to be medically indicated. ${ }^{4-7}$ In 2008, 29\% of births in China were by caesarean section, increasing to $35 \%$ by 2014. ${ }^{8}$ National averages hide huge variation however: in 2014 the caesarean section rate was as high as $62 \%$ in the north eastern province of Jilin, while it was only $4 \%$ in Tibet. $^{8}$

Overuse of caesarean section adversely affects the health of the mother and the child, ${ }^{910}$ although evidence from China is limited. ${ }^{4}$ Caesarean sections in China have been associated with childhood obesity ${ }^{11}$ and 
postpartum depression, ${ }^{12}$ but evidence that caesarean sections are associated with adverse psychological development in children is unconvincing. ${ }^{13}$ A large study in Shanghai found no difference in the frequency of severe maternal complications in women who underwent caesarean delivery on maternal request compared with women who tried vaginal delivery. ${ }^{14}$

The reasons underlying the high caesarean section rates in China are complex, with both demand and supply side factors driving the rate. ${ }^{4} 75$ Women may request a caesarean section because they fear the consequences of vaginal delivery or they think a caesarean section is safer. ${ }^{5} 16$ Perverse financial incentives that encourage costly procedures have certainly been important, as have medicolegal concerns. ${ }^{17}$ Total expenditure on caesarean section has increased noticeably and the procedure has become an important source of revenue for hospitals and healthcare providers. ${ }^{1618}$ The increased funding available through insurance schemes may also have boosted demand, although evidence that health insurance has encouraged caesarean section is weak. $^{2} 619$ The facility based doctor led model of maternal healthcare where women give birth in large hospitals replete with advanced technology and costly interventions might also have contributed to the high rates. $^{31520}$

In the past 10 years, the Chinese government has become increasingly concerned about rising caesarean section rates, and various policies and programmes have been put in place at central, provincial, district, county, and hospital levels. ${ }^{8}$ 21-23 Concerns about increasing caesarean section rates intensified particularly from 2010 onwards after the publication of a report that showed China had one of the highest caesarean section rates in the world. ${ }^{24}$ Appendix table 1 shows examples of specific policies. Interventions include hands-on training for doctors and midwives, the revision of guidelines for the management of dystocia, education of women on the advantages of natural birth and the risk of caesarean delivery, audits of caesarean sections without indications, removing financial incentives for caesarean sections, setting targets for a maximum caesarean section rate, and linking the success in reaching targets to financial and other incentives. ${ }^{82122}$ ${ }^{25}$ Although overall caesarean section rates continued to increase until 2014, the speed of change slowed and rates started to decline in large urban areas and in areas with very high caesarean section rates in $2008 .^{8}$ 2122 In Beijing, the caesarean section rate declined from $60 \%$ in 2009 to $43 \%$ in 2014 . Similar figures for Shanghai are $67 \%$ and $52 \%$, respectively. ${ }^{8}$

As China relaxed its one child policy in November $2013,{ }^{26}$ and many Chinese couples are now allowed and encouraged to have a second child, the careful monitoring of caesarean sections becomes more urgent. As the number of repeat caesarean sections increase, the risk to benefit ratio of a caesarean section may well change. ${ }^{27} 28$ Evidence on how the changes in the one child policy have affected the obstetric risk distribution of women giving birth is, however, lacking. If obstetric risk changes, the need for caesarean sections might change, caesarean sections might become less safe, and perinatal and pregnancy related mortality might increase.

We examined how the relaxation of the one child policy and policies to reduce caesarean sections might have affected trends in caesarean section rates and perinatal and pregnancy related mortality rates in hospitals in China between 2012 and 2016. We take account of the effects of the relaxation of the one child policy by adjusting all time trends for changes in the obstetric profile of women, including age and parity, and by reporting trends in nulliparous and multiparous women separately.

\section{Methods}

\section{Data sources}

We used three data sources: individual level data collected through China's National Maternal Near Miss Surveillance System (NMNMSS) covering births in hospital between 1 January 2012 and 31 December 2016; institutional data collected from each hospital through the NMNMSS in 2015; and a survey conducted in 2016 inquiring about policies that may have influenced caesarean section rates in the sampled hospitals.

The NMNMSS covers 441 hospitals at county level or above; however, we excluded three hospitals who did not report any data after 2012. The sampling strategy has been detailed elsewhere. ${ }^{29}$ In 2010 the NMNMSS sampled 273 urban districts and rural counties randomly from the National Maternal and Child Mortality Surveillance System (fig 1). At the same time 53 counties and districts that were part of the provincial Maternal and Child Mortality Surveillance System were added to ensure proportional representation of urban and rural populations across all three regions in China. Within each of the sampled districts or counties, two health facilities with more than 1000 deliveries each year were randomly selected (or one facility if only one was available). Because some districts or counties did

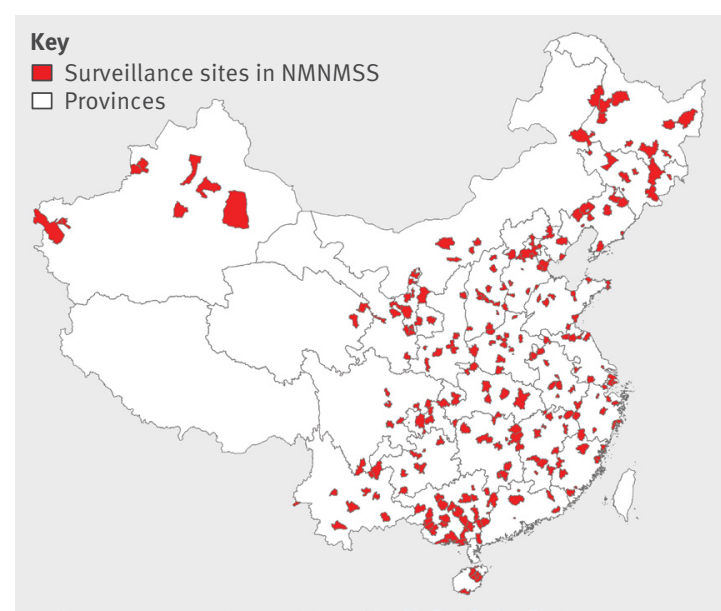

Fig 1 | Map of sites in National Maternal Near Miss Surveillance System in mainland China, 2012-16 
not have hospitals with the necessary number of births, large hospitals in urban districts were oversampled. As a result, urban populations were over-represented in the NMNMSS, particularly in central and western regions. Within each hospital, sociodemographic and obstetric information were collected prospectively on all pregnant or postpartum women admitted to the obstetric department. Doctors responsible for patient care collected data, which included the date of delivery, the number of antenatal visits, maternal education and marital status, maternal age, birth order, gestational age at delivery (based on date of last menstrual period or ultrasonography findings), mode of delivery, presentation of the fetus, single or multiple pregnancy, maternal complications (at any time during hospital admission), and the birth weight of the baby.

In 2015 the NMNMSS collected standard data on each hospital, including whether the hospital was located in an urban district or a rural county, the level of the hospital (levels 1-3 based on the number of beds (level 3 hospitals have more beds than level 1 and 2 hospitals), categories of clinical departments, numbers of medical staff, type and quantity of equipment, and hospital funding), ${ }^{30}$ and the number of obstetricians.

In 2016, we conducted a survey of caesarean section policies in all the surveillance hospitals. Through this survey we documented policies established by the national or local health administrative department or the administrative department of the hospital, which aimed to reduce the caesarean section rates in the hospital. The survey was conducted during the national training of NMNMSS staff in October 2016, which brings together all staff responsible for the surveillance work in the hospitals. The structured survey questionnaire included information on whether the hospitals had any policy to reduce the caesarean section rate, including whether the hospitals had a list of medical indications for caesarean sections and whether the hospitals had an upper target for the caesarean section rate.

\section{Definition of variables}

We used commonly used definitions for maternal age, marital status, and education. ${ }^{29}$ We classified maternal complications into mutually exclusive categories of direct obstetric complications and medical diseases. Direct obstetric complications included uterine rupture, placenta praevia, abruptio placentae, unspecified antepartum haemorrhage, pre-eclampsia, eclampsia, HELLP syndrome, or any fetal malpresentation (breech, shoulder, or other). Medical diseases included heart disease, embolism/thrombophlebitis, hepatic disease, severe anaemia (haemoglobin $<70 \mathrm{~g} / \mathrm{L}$ ), renal disease (including urinary tract infection), lung disease (including upper respiratory tract infection), HIV/AIDS, connective tissue disorders, gestational diabetes mellitus, and cancer.

We categorised women into risk groups for caesarean section using a modified version of the Robson classification. ${ }^{3132}$ Because there is no agreement on the optimal caesarean section rate in the population, and indications for caesarean sections are not standardised, Robson proposed a system that classifies women into 10 groups based on their obstetric characteristics (parity, previous caesarean section, gestational age, onset of labour, fetal presentation, and number of fetuses). ${ }^{31}$ The size of each group and the caesarean section rate within each group correspond to an expected range. Monitoring caesarean sections within the Robson groups therefore allows the evaluation of clinical practice, including whether the caesarean section rate is justified. We adapted Robson's classification because the NMNMSS did not collect information on whether or not the labour was induced. We created eight mutually exclusive categories: nulliparous, singleton, cephalic, $\geq 37$ weeks' gestation; multiparous, singleton, cephalic, $\geq 37$ weeks' gestation without a uterine scar; uterine scar, singleton, cephalic, $\geq 37$ weeks' gestation; all nulliparous women with a singleton breech; all multiparous women with a singleton breech, including those with a uterine scar; all multiple pregnancies, including those with uterine scar; all women with a single pregnancy in other abnormal lie, including those with uterine scar; and all singleton, cephalic, $\leq 36$ weeks' gestation pregnancies, including those with uterine scar.

For the institutional data we calculated the number of obstetricians per 1000 births using the number of births reported in the NMNMSS in 2015. We also report the region in which the hospital is located, using China's standard definitions for region (western, central, and eastern). ${ }^{33}$ We extracted the day of the week from the date of delivery.

We report the number of perinatal deaths (stillbirths and early neonatal deaths within seven days of delivery before discharge), pregnancy related deaths, and uterine rupture. Stillbirths were defined as reported previously. ${ }^{29}$ Pregnancy related deaths were defined as deaths from any cause in women who died after 28 completed weeks of gestation or with a fetus of birth weight $1000 \mathrm{~g}$ or higher (including women who died undelivered). Uterine rupture was defined as uterine or lower uterine dehiscence in late pregnancy or during childbirth, including complete and incomplete rupture. $^{34}$

\section{Statistical analysis}

We restricted the analysis to women who delivered at or after 28 completed weeks of gestation or with a fetus of birth weight $1000 \mathrm{~g}$ or higher, consistent with the definition of the perinatal period in China. ${ }^{35}$ Since the NMNMSS oversampled large urban hospitals, we weighed the caesarean section rate for the sampling distribution of the population according to the 2010 census of China, as detailed elsewhere. ${ }^{29}$ We used Poisson regression with a robust variance estimator in STATA version 13.1 to examine the strength of association between institutional and women's characteristics and the proportion of caesarean sections, reporting the findings from three models. Model 1 describes the crude relative risk and 95\% confidence intervals, taking account of the NMNMSS 
sampling strategy and clustering of births within hospitals. ${ }^{36}$ Model 2 adjusts the effect estimates described in model 1 for institutional (region, hospital level, number of obstetricians per 1000 births, day of the week) and individual socioeconomic characteristics (number of antenatal visits, education, marital status). In model 3, we further adjust the relative risks for individual demographic and clinical factors that are known to be associated with caesarean sections and that might have changed after the relaxation of the one child policy: maternal age, Robson classification, maternal complications, and birth weight. We did not adjust for parity separately because such adjustment is built into the Robson classification. To identify the most robust and stable model we investigated both multicollinearity and model goodness-of-fit.

To examine whether trends over time in caesarean sections were similar within maternal age groups, in nulliparous and multiparous women, in each Robson group, and by the caesarean section rate in the hospital in 2012, we repeated models 1 and 3 testing for an interaction between year and each of these exposures. We obtained the $\mathrm{P}$ value for the interaction terms by comparing models with and without interaction terms using a likelihood ratio test. We also report changes in the age, parity, and Robson distributions of women over time.

To examine trends over time in perinatal and pregnancy related mortality we repeated models 1 and 3 against these outcomes, restricting the sample to singleton births for perinatal deaths and to all births for pregnancy related deaths. We repeated the analysis in nulliparous and multiparous women separately, adding an interaction term. We also report the incidence of uterine rupture over time among nulliparous, multiparous women with a uterine scar, and multiparous women without a uterine scar, using models 1 and 3 (but removing the Robson classification and complications from the model).

Lastly, we describe the proportion of hospitals reporting a policy to reduce caesarean section rates, including whether or not a target has been set for caesarean section or whether clinical indications for caesarean sections have been defined. We also report the median cost of caesarean sections and vaginal deliveries.

\section{Patient involvement}

No patients were involved in setting the research question or the outcome measures, nor were they involved in developing plans for design or implementation of the study. No patients were asked to advise on interpretation or writing up of results. There are no plans to disseminate the results of the research to study participants or the relevant patient community.

\section{Results}

Changes over time in the obstetric risk population Between 2012 and 2016 there were 6838582 deliveries at 28 completed weeks or more of gestation or with a fetus of birth weight $1000 \mathrm{~g}$ or more in 438 hospitals in the NMNMSS. Substantial changes occurred over time in the age and parity distributions of the women, the proportion of women with a uterine scar, and the proportion of women in each modified Robson group (table 1). The proportion of births to women aged 35 or more increased from $7.8 \%$ in 2012 to $10.9 \%$ in 2016 (table 1). More importantly, the proportion of births of birth order two or more increased from 34.1\% in 2012 to $46.7 \%$ in 2016 , and the proportion of women with a uterine scar nearly doubled, from $9.8 \%$ to $17.7 \%$ (table 1). Correspondingly, the greatest change in individual Robson groups was in the proportion of women with a uterine scar and a singleton birth at term (from $8.6 \%$ to $15.6 \%$ ).

\section{Determinants of caesarean sections}

Three million (3078101) women delivered by caesarean section, giving a weighted caesarean section rate of $43.5 \%$. Caesarean section rates were higher in hospitals located in urban areas than in rural areas (see appendix table 2). Level 3 referral hospitals did more caesarean sections than lower level hospitals, but this was fully explained by the varying sociodemographic and obstetric characteristics of the women seeking care in these hospitals (adjusted relative risk comparing level 3 and level 2 hospitals 1.04, 95\% confidence interval 0.98 to 1.10). Hospitals with six or more obstetricians per 1000 births had the highest caesarean section rates, and this effect persisted after adjustment for the level of hospital and the sociodemographic and obstetric profile of the women (adjusted relative risk comparing hospitals with $\geq 6$ obstetricians per 1000 births with hospitals with $<4$ obstetricians per 1000 births $1.15,1.08$ to 1.23$)$. Caesarean sections were less common on Sundays (adjusted relative risk $0.89,0.88$ to 0.91$)$ and Saturdays $(0.93,0.92$ to 0.95$)$ compared with Wednesdays. The lowest caesarean section rates were among women with few antenatal visits (caesarean rate $35.8 \%$ ), those with no education (35.2\%), and unmarried women (28.8\%).

Caesarean section rates increased noticeably with maternal age. The caesarean section rate in women younger than 20 was $27.5 \%$ (crude relative risk compared with women aged 25-29 0.64, 95\% confidence interval 0.61 to 0.68 ) whereas the rate in women aged 40 or older was $60.7 \%(1.42,1.38$ to 1.45). These differences persisted after adjustment for institutional, sociodemographic, and obstetric factors. As expected, caesarean section rates were high in women with direct obstetric complications (83.1\%) or medical diseases $(51.2 \%)$, but they were also high (40.1\%) among women in whom the hospital record noted no such complications. The caesarean section rate was lowest among multiparous women without a uterine scar with a singleton cephalic birth at term (19.5\%), and highest among women with a uterine scar who had a singleton cephalic birth at term (91.2\%).

\section{Trends over time in caesarean section rates}

The caesarean section rate declined from $45.3 \%$ in 2012 to $41.1 \%$ in 2016 (crude relative risk 0.91, 95\% 


\begin{tabular}{|c|c|c|c|c|c|c|}
\hline Obstetric risk category & 2012 & 2013 & 2014 & 2015 & 2016 & $P$ value* \\
\hline \multicolumn{7}{|l|}{ Parity† } \\
\hline Nulliparous & $862217(65.9)$ & $816344(63.9)$ & $895213(61.4)$ & $725501(56.3)$ & $802064(53.3)$ & \multirow{3}{*}{0.00} \\
\hline Multiparous: & & & & & & \\
\hline All & $445981(34.1)$ & 460507 (36.1) & $562796(38.6)$ & $564200(43.7)$ & $701340(46.7)$ & \\
\hline With uterine scar $\neq$ & $128107(9.8)$ & $139963(11.0)$ & $187792(12.9)$ & 200647 (15.6) & $265770(17.7)$ & - \\
\hline Without uterine scar $\neq$ & 316197 (24.2) & $319343(25.0)$ & $374547(25.7)$ & $362943(28.1)$ & 435009 (28.9) & - \\
\hline \multicolumn{7}{|l|}{ Age of women (years)§ } \\
\hline$<20$ & $41858(3.3)$ & $43187(3.5)$ & $43028(3.1)$ & 40605 (3.3) & $35366(2.4)$ & \multirow{5}{*}{0.00} \\
\hline $20-24$ & $349457(27.9)$ & $325386(26.3)$ & $319525(22.8)$ & $262980(21.2)$ & $250310(17.0)$ & \\
\hline $25-29$ & $513358(41.0)$ & $507324(41.1)$ & $621081(44.3)$ & $533712(43.0)$ & $668158(45.4)$ & \\
\hline $30-34$ & 248965 (19.9) & $254754(20.6)$ & $299535(21.3)$ & $276325(22.2)$ & $356108(24.2)$ & \\
\hline$\geq 35$ & $97962(7.8)$ & $105117(8.5)$ & $120366(8.6)$ & $128967(10.4)$ & $160570(10.9)$ & \\
\hline \multicolumn{7}{|l|}{ Modified Robson classification } \\
\hline Nulliparous, single, cephalic, $\geq 37$ weeks & $766609(58.5)$ & $726029(56.9)$ & $797725(54.7)$ & $642367(49.8)$ & $712263(47.4)$ & \multirow{10}{*}{0.00} \\
\hline $\begin{array}{l}\text { Multiparous, single, cephalic, } \geq 37 \text { weeks, } \\
\text { without uterine scar }\end{array}$ & $278219(21.2)$ & $281463(22.0)$ & $332501(22.8)$ & $323137(25.1)$ & 388804 (25.9) & \\
\hline Uterine scar, single, cephalic, $\geq 37$ weeks & $112136(8.6)$ & $122332(9.6)$ & $164699(11.3)$ & $176078(13.7)$ & $233971(15.6)$ & \\
\hline Nulliparous, single, breech & $29361(2.2)$ & $26943(2.1)$ & $28810(2.0)$ & 23925 (1.9) & $25756(1.7)$ & \\
\hline $\begin{array}{l}\text { Multiparous, single, breech, including those } \\
\text { with uterine scar }\end{array}$ & $13152(1.0)$ & $13185(1.0)$ & $14944(1.0)$ & $14784(1.2)$ & $17676(1.2)$ & \\
\hline $\begin{array}{l}\text { All multiple pregnancies, including those } \\
\text { with uterine scar }\end{array}$ & $21550(1.7)$ & $22013(1.7)$ & $25820(1.8)$ & $24050(1.9)$ & $26152(1.7)$ & \\
\hline $\begin{array}{l}\text { All single, other abnormal lies, including } \\
\text { those with uterine scar }\end{array}$ & $3105(0.2)$ & $3274(0.3)$ & $3874(0.3)$ & $3636(0.3)$ & $3816(0.3)$ & \\
\hline $\begin{array}{l}\text { All single, cephalic, } \leq 36 \text { weeks, including } \\
\text { those with uterine scar }\end{array}$ & $76438(5.8)$ & $74773(5.9)$ & $83295(5.7)$ & $75620(5.9)$ & $88349(5.9)$ & \\
\hline Cannot be classified & $9143(0.7)$ & $7043(0.6)$ & $6593(0.5)$ & $6326(0.5)$ & $6843(0.5)$ & \\
\hline All & $1309713(100.0)$ & $1277055(100.0)$ & $1458261(100.0)$ & $1289923(100.0)$ & $1503630(100.0)$ & \\
\hline \multicolumn{7}{|c|}{$\begin{array}{l}{ }^{*} x^{2} \text { test. } \\
\text { †No information on parity for } 2419(0.04 \%) \text { births. } \\
\text { fNo information on uterine scar for } 4506(0.07 \%) \text { births. } \\
\text { §No information on maternal age for } 234578(3.4 \%) \text { births. }\end{array}$} \\
\hline
\end{tabular}

confidence interval 0.89 to 0.93 ; table 2). Adjusting the time trends for institutional, sociodemographic, and obstetric characteristics reduced the relative risk to 0.82 ( 0.81 to 0.84 ), suggesting that caesarean section rates declined by $18 \%$ between 2012 and 2016 .
Table 2 and appendix table 3 show the trends over time in caesarean section rates within parity and age groups. Crude caesarean section rates declined in nulliparous women (crude relative risk 0.81, 0.79 to 0.84) and in multiparous women without a uterine

\begin{tabular}{|c|c|c|c|c|c|c|}
\hline Variables & 2012 & 2013 & 2014 & 2015 & 2016 & $\begin{array}{l}\text { P value } \\
\text { (interaction) }\end{array}$ \\
\hline \multicolumn{7}{|c|}{ Weighted caesarean section rate (\%) (No of caesarean sections, \% of caesarean sections) } \\
\hline All & $45.3(617460,100.0)$ & $45.6(606607,100.0)$ & $43.8(660154,100.0)$ & $42.1(561127,100.0)$ & $41.1(632753,100.0)$ & \multirow{4}{*}{-} \\
\hline Nulliparous & $46.6(415530,67.4)$ & $46.7(393807,64.9)$ & $43.3(397980,60.3)$ & $40.5(300413,53.6)$ & $37.9(308308,48.7)$ & \\
\hline $\begin{array}{l}\text { Multiparous without uterine } \\
\text { scar }\end{array}$ & $25.4(84711,13.8)$ & $24.9(84600,14.0)$ & $22.7(90494,13.7)$ & $20.5(78339,14.0)$ & $18.5(84100,13.3)$ & \\
\hline Multiparous with uterine scar & $90.3(116049,18.8)$ & $90.9(127559,21.1)$ & $91.0(171257,26.0)$ & $90.5(181811,32.4)$ & $90.4(239892,37.9)$ & \\
\hline \multicolumn{7}{|c|}{ Crude relative risk $(95 \% \mathrm{Cl}):$ model 1} \\
\hline All & 1.00 & $1.01(0.99$ to 1.02$)$ & 0.97 (0.95 to 0.98) & $0.93(0.91$ to 0.95$)$ & $0.91(0.89$ to 0.93$)$ & - \\
\hline Nulliparous & 1.00 & $1.00(0.99$ to 1.02$)$ & $0.93(0.91$ to 0.95$)$ & $0.87(0.85$ to 0.89$)$ & $0.81(0.79$ to 0.84$)$ & \multirow{3}{*}{0.00} \\
\hline $\begin{array}{l}\text { Multiparous without uterine } \\
\text { scar }\end{array}$ & 1.00 & $0.98(0.92$ to 1.01$)$ & 0.89 (0.86 to 0.93$)$ & $0.81(0.77$ to 0.84$)$ & $0.73(0.70$ to 0.76$)$ & \\
\hline Multiparous with uterine scar & 1.00 & $1.01(1.00$ to 1.01$)$ & 1.01 (1.00 to 1.01$)$ & $1.00(1.00$ to 1.01$)$ & $1.00(0.99$ to 1.01$)$ & \\
\hline \multicolumn{7}{|c|}{ Adjusted relative risk $(95 \% \mathrm{Cl}):$ model 3} \\
\hline All & 1.00 & 0.99 (0.98 to 1.00$)$ & $0.93(0.91$ to 0.94$)$ & $0.87(0.86$ to 0.89$)$ & $0.82(0.81$ to 0.84$)$ & - \\
\hline Nulliparous* & 1.00 & $0.99(0.98$ to 1.01$)$ & $0.91(0.89$ to 0.93$)$ & $0.85(0.83$ to 0.87$)$ & $0.78(0.76$ to 0.80$)$ & \multirow[b]{2}{*}{0.00} \\
\hline $\begin{array}{l}\text { Multiparous without uterine } \\
\text { scar* }\end{array}$ & 1.00 & $0.97(0.95$ to 1.00$)$ & $0.88(0.85$ to 0.91$)$ & $0.78(0.75$ to 0.82$)$ & $0.69(0.66$ to 0.72$)$ & \\
\hline $\begin{array}{l}\text { Multiparous with uterine } \\
\text { scar* }\end{array}$ & 1.00 & $1.00(1.00$ to 1.01$)$ & $1.00(1.00$ to 1.01$)$ & $0.99(0.99$ to 1.00$)$ & 0.99 (0.98 to 0.99) & \\
\hline
\end{tabular}

6925 (0.1\%) births had no information on parity and presence of uterine scar.

*Model 3 without adjustment for Robson classification. 
scar $(0.73,0.70$ to 0.76 ; interaction parity and year, $\mathrm{P}=0.00$; table 2). Adjustment for sociodemographic and obstetric factors further strengthened the relative risk. Caesarean section rates declined in all age groups, although the speed of decline was greater in younger women than in older women (interaction age and year, $\mathrm{P}=0.00$; see appendix table 3 ).

Table 3 shows trends over time in caesarean section rates in each modified Robson group. Caesarean section rates declined substantially in two groups: nulliparous women with a singleton, cephalic birth at $\geq 37$ weeks of gestation (from $45.0 \%$ to $35.2 \%$, adjusted relative risk $0.75,95 \%$ confidence interval 0.73 to 0.77 ) and multiparous women without a uterine scar and a single cephalic birth at term (from $22.9 \%$ to $15.6 \%$, 0.65, 0.62 to 0.68 ), Women in other Robson groups did not experience such declines (interaction Robson groups and year, $\mathrm{P}=0.00$ ).

Caesarean section rates declined particularly in women giving birth in hospitals with high caesarean section rates in 2012 (table 4). For example, in hospitals with a caesarean section rate of $60 \%$ or more in 2012 rates decreased from $68.8 \%$ in 2012 to $56.8 \%$ in 2016 (adjusted relative risk $0.78,0.75$ to 0.81 ). In hospitals with moderately high caesarean section rates (baseline rates of 20-39\%), however, the rates remained stable over time, although adjustment for sociodemographic and obstetric factors resulted in an adjusted relative risk of 0.90 (0.87 to 0.93$)$. In hospitals with relatively low caesarean section rates in 2012 rates continued to increase over time $(1.17,1.04$ to 1.31$)$; interaction baseline caesarean section rate and year $\mathrm{P}=0.00$ ).

\section{Trends over time in perinatal and maternal} outcomes

Perinatal mortality declined substantially (table 5), from 10.1 per 1000 births in 2012 to 7.2 per 1000 births in 2016 (crude relative risk $0.72,95 \%$ confidence interval 0.67 to 0.77 ). These trends persisted after adjustment for sociodemographic and obstetric factors

\begin{tabular}{|c|c|c|c|c|c|c|}
\hline Variables & 2012 & 2013 & 2014 & 2015 & 2016 & $\begin{array}{l}\text { P value } \\
\text { (interaction) }\end{array}$ \\
\hline \multicolumn{7}{|c|}{ Weighted caesarean section rate (\%) (No of caesarean sections, \% of caesarean sections) } \\
\hline $\begin{array}{l}\text { Nulliparous, single, } \\
\text { cephalic, } \geq 37 \text { weeks }\end{array}$ & $45.0(356895,58.1)$ & $44.9(336887,55.7)$ & $41.2(336391,51.1)$ & $38.0(248107,44.4)$ & $35.2(252285,40.0)$ & \\
\hline $\begin{array}{l}\text { Multiparous, single, } \\
\text { cephalic, } \geq 37 \text { weeks, } \\
\text { without uterine scar }\end{array}$ & $22.9(66742,10.9)$ & $22.3(66250,11.0)$ & $20.1(70308,10.7)$ & $17.7(59648,10.7)$ & $15.6(62625,9.9)$ & \\
\hline $\begin{array}{l}\text { Uterine scar, single, } \\
\text { cephalic, } \geq 37 \text { weeks }\end{array}$ & $91.0(102546,16.7)$ & $91.6(112518,18.6)$ & $91.7(151455,23.0)$ & $91.1(160776,28.8)$ & $90.9(212702,33.8)$ & \\
\hline $\begin{array}{l}\text { Nulliparous, single, breech/ } \\
\text { multiparous, single, breech/ } \\
\text { all multiple pregnancies/all } \\
\text { single other abnormal lies }\end{array}$ & $83.3(56426,9.2)$ & $84.3(55583,9.2)$ & $85.0(62683,9.5)$ & $84.6(56391,10.1)$ & $85.0(62605,9.9)$ & \\
\hline $\begin{array}{l}\text { All single, cephalic, } \geq 36 \\
\text { weeks }\end{array}$ & $39.4(31994,5.2)$ & $41.9(33146,5.5)$ & $42.2(37190,5.7)$ & $42.3(33831,6.1)$ & $43.1(39911,6.3)$ & \\
\hline \multicolumn{7}{|c|}{ Crude relative risk $(95 \% \mathrm{Cl})$ : Model 1} \\
\hline $\begin{array}{l}\text { Nulliparous, single, } \\
\text { cephalic, } \geq 37 \text { weeks }\end{array}$ & 1.00 & $1.00(0.98$ to 1.02$)$ & $0.92(0.90$ to 0.94$)$ & $0.84(0.82$ to 0.87$)$ & $0.78(0.76$ to 0.81$)$ & \multirow{5}{*}{0.00} \\
\hline $\begin{array}{l}\text { Multiparous, single, } \\
\text { cephalic, } \geq 37 \text { weeks, } \\
\text { without uterine scar }\end{array}$ & 1.00 & $0.97(0.94$ to 1.01$)$ & 0.88 (0.84 to 0.92$)$ & 0.77 (0.73 to 0.82) & $0.68(0.65$ to 0.71$)$ & \\
\hline $\begin{array}{l}\text { Uterine scar, single, } \\
\text { cephalic, } \geq 37 \text { weeks }\end{array}$ & 1.00 & 1.01 (1.00 to 1.01$)$ & 1.01 (1.00 to 1.01) & $1.00(0.99$ to 1.01$)$ & $1.00(0.99$ to 1.01$)$ & \\
\hline $\begin{array}{l}\text { Nulliparous, single, breech/ } \\
\text { multiparous, single, breech/ } \\
\text { all multiple pregnancies/all } \\
\text { single other abnormal lies }\end{array}$ & 1.00 & $1.01(1.00$ to 1.02$)$ & $1.02(1.01$ to 1.03$)$ & $1.02(1.01$ to 1.03$)$ & $1.02(1.01$ to 1.03$)$ & \\
\hline $\begin{array}{l}\text { All single, cephalic, } \\
\leq 36 \text { weeks }\end{array}$ & 1.00 & $1.06(1.04$ to 1.08$)$ & 1.07 (1.04 to 1.10$)$ & $1.07(1.04$ to 1.11$)$ & 1.09 (1.06 to 1.13$)$ & \\
\hline \multicolumn{7}{|c|}{ Adjusted relative risk $(95 \% \mathrm{Cl}):$ Model 3* } \\
\hline $\begin{array}{l}\text { Nulliparous, single, } \\
\text { cephalic, } \geq 37 \text { weeks }\end{array}$ & 1.00 & $0.99(0.97$ to 1.01$)$ & $0.90(0.88$ to 0.92$)$ & $0.83(0.81$ to 0.85$)$ & $0.75(0.73$ to 0.77$)$ & \multirow{5}{*}{0.00} \\
\hline $\begin{array}{l}\text { Multiparous, single, } \\
\text { cephalic, } \geq 37 \text { weeks, } \\
\text { without uterine scar }\end{array}$ & 1.00 & $0.97(0.94$ to 1.00$)$ & $0.87(0.83$ to 0.90$)$ & 0.75 (0.72 to 0.79$)$ & 0.65 (0.62 to 0.68$)$ & \\
\hline $\begin{array}{l}\text { Uterine scar, single, } \\
\text { cephalic, } \geq 37 \text { weeks }\end{array}$ & 1.00 & $1.00(1.00$ to 1.01$)$ & $1.00(1.00$ to 1.01$)$ & $0.99(0.99$ to 1.00$)$ & 0.99 (0.98 to 0.99) & \\
\hline $\begin{array}{l}\text { Nulliparous, single, breech/ } \\
\text { multiparous, single, breech/ } \\
\text { all multiple pregnancies/all } \\
\text { single other abnormal lies }\end{array}$ & 1.00 & 1.01 (1.00 to 1.01$)$ & 1.01 (1.00 to 1.01$)$ & $1.00(0.99$ to 1.01$)$ & $0.99(0.98$ to 1.00$)$ & \\
\hline $\begin{array}{l}\text { All single, cephalic, } \\
\leq 36 \text { weeks }\end{array}$ & 1.00 & $1.03(1.01$ to 1.05$)$ & $1.00(0.97$ to 1.03$)$ & $0.98(0.95$ to 1.01$)$ & 0.96 (0.93 to 0.99) & \\
\hline
\end{tabular}




\begin{tabular}{|c|c|c|c|c|c|c|}
\hline $\begin{array}{l}\text { Variables by caesarean } \\
\text { section rate in hospital } \\
\text { in } 2012\end{array}$ & 2012 & 2013 & 2014 & 2015 & 2016 & $\begin{array}{l}\mathrm{P} \text { value } \\
\text { (interaction) }\end{array}$ \\
\hline \multicolumn{7}{|c|}{ Weighted caesarean section rate (\%) (No of caesarean sections, \% of caesarean sections) } \\
\hline$<20 \%$ & $14.2(6327,1.0)$ & $15.2(6842,1.1)$ & $17.1(8389,1.3)$ & $17.6(8312,1.5)$ & $18.3(8454,1.4)$ & \multirow[t]{4}{*}{-} \\
\hline $20-39 \%$ & $32.1(117606,19.1)$ & $33.2(118858,19.6)$ & $31.8(122411,18.7)$ & $31.8(115493,20.8)$ & $31.8(128124,20.5)$ & \\
\hline $40-59 \%$ & $49.2(327517,53.0)$ & $49.9(323588,53.4)$ & $47.0(349406,53.3)$ & $45.5(294078,53.1)$ & $43.6(336082,53.8)$ & \\
\hline$\geq 60 \%$ & $68.8(166010,26.9)$ & $67.1(157075,25.9)$ & $63.4(174995,26.7)$ & $60.8(135961,24.6)$ & $56.8(151877,24.3)$ & \\
\hline \multicolumn{7}{|c|}{ Crude relative risk $(95 \% \mathrm{Cl}):$ Model 1} \\
\hline$<20 \%$ & 1.00 & 1.07 (0.96 to 1.19$)$ & $1.20(1.08$ to 1.34$)$ & $1.24(1.11$ to 1.39$)$ & $1.28(1.14$ to 1.45$)$ & \multirow{4}{*}{0.00} \\
\hline $20-39 \%$ & 1.00 & $1.04(1.01$ to 1.06$)$ & $0.99(0.96$ to 1.02$)$ & $0.99(0.96$ to 1.02$)$ & $0.99(0.96$ to 1.03$)$ & \\
\hline $40-59 \%$ & 1.00 & $1.01(1.00$ to 1.03$)$ & $0.95(0.94$ to 0.97$)$ & $0.92(0.90$ to 0.94$)$ & $0.89(0.87$ to 0.91$)$ & \\
\hline$\geq 60 \%$ & 1.00 & $0.98(0.95$ to 1.00$)$ & $0.92(0.90$ to 0.95$)$ & $0.88(0.86$ to 0.91$)$ & $0.82(0.79$ to 0.86$)$ & \\
\hline \multicolumn{7}{|c|}{ Adjusted relative risk $(95 \% \mathrm{Cl}):$ Model 3} \\
\hline$<20 \%$ & 1.00 & $1.06(0.96$ to 1.17$)$ & $1.15(1.02$ to 1.29$)$ & 1.19 (1.08 to 1.32$)$ & 1.17 (1.04 to 1.31$)$ & \multirow{4}{*}{0.00} \\
\hline $20-39 \%$ & 1.00 & $1.02(0.99$ to 1.04$)$ & 0.95 (0.92 to 0.98$)$ & $0.93(0.89$ to 0.96$)$ & $0.90(0.87$ to 0.93$)$ & \\
\hline $40-59 \%$ & 1.00 & $1.00(0.98$ to 1.01$)$ & $0.92(0.90$ to 0.94$)$ & $0.86(0.84$ to 0.88$)$ & $0.81(0.79$ to 0.83$)$ & \\
\hline$\geq 60 \%$ & 1.00 & 0.97 (0.94 to 0.99) & $0.90(0.87$ to 0.93$)$ & $0.85(0.82$ to 0.88$)$ & $0.78(0.75$ to 0.81$)$ & \\
\hline
\end{tabular}

(adjusted relative risk $0.87,0.83$ to 0.91 ). Perinatal mortality declined at the same rate in nulliparous and multiparous women (interaction parity and year $\mathrm{P}=0.48$ ). There was no change in pregnancy related mortality over time (from 7.7 per 100000 in 2012 to 7.1 per 100000 in 2016, crude relative risk 0.91, 0.64 to 1.30 ; table 6 ).

Table 7 shows trends in the incidence of uterine rupture. The incidence of uterine rupture was much higher in women with a uterine scar than in those without a scar. Among women with a uterine scar the incidence of uterine rupture increased steadily, from 28.4 per 10000 births in 2012 to 87.3 per 10000 births in 2106 (adjusted relative risk 2.83, 95\% confidence interval 1.89 to 4.23). Among nulliparous women, there was an increase in the incidence of uterine rupture between 2012 and 2013, but rates remained relatively stable thereafter.

\section{Survey on policies to reduce caesarean section rates}

Overall, 398 (90.9\%) hospitals completed the survey on policies potentially influencing caesarean section rates (see appendix table 4). The cost of caesarean sections (median ¥5000; £562; \$788; €635) was twice as high as the cost of vaginal deliveries (median $¥ 2500$ ). Nearly all $(92.7 \%)$ hospitals reported that they had a policy to reduce caesarean sections, two thirds $(67.1 \%)$ had set a target caesarean section rate, and nearly all reported that they had a list of clinical indications for caesarean sections $(93.0 \%)$, trained health providers in the use of caesarean sections (86.9\%), or offered health education to women (95.0\%).

\section{Discussion}

Using data from more than six million births in 438 large hospitals in China, we found that caesarean section rates declined steadily between 2012 and 2016 (crude relative risk 0.91, 95\% confidence interval 0.89 to 0.93 ), reaching an overall hospital based rate of $41.1 \%$ in 2016 . The relaxation of the one child policy in China led to an increase in the proportion of multiparous births (from 34.1\% in 2012 to 46.7\% in 2016), and births in women with a uterine scar nearly doubled (from $9.8 \%$ to $17.7 \%$ of all births). Taking account of these changes amplified the decline in caesarean sections over time (adjusted relative risk $0.82,95 \%$ confidence interval 0.81 to 0.84 ), suggesting that caesarean sections declined by 18\% between 2012 and 2016. The fall in caesarean

\begin{tabular}{|c|c|c|c|c|c|c|}
\hline Variables & 2012 & 2013 & 2014 & 2015 & 2016 & $\begin{array}{l}\text { P value } \\
\text { (interaction) }\end{array}$ \\
\hline \multicolumn{7}{|c|}{ Weighted perinatal mortality rate (per 1000 births) (No of deaths) } \\
\hline All & $10.1(13849)$ & $9.5(12836)$ & $8.4(12917)$ & $8.3(11354)$ & $7.2(11443)$ & \multirow[t]{3}{*}{ - } \\
\hline Nulliparous & $8.7(7925)$ & $8.3(7092)$ & $7.4(6887)$ & $7.3(5525)$ & $6.4(5329)$ & \\
\hline Multiparous & $12.3(5901)$ & $11.4(5738)$ & $9.8(6023)$ & $9.5(5825)$ & $8.1(6110)$ & \\
\hline \multicolumn{7}{|c|}{ Crude relative risk $(95 \% \mathrm{Cl})$ : Model 1} \\
\hline All & 1.00 & 0.94 (0.91 to 0.98$)$ & $0.83(0.79$ to 0.88$)$ & $0.82(0.78$ to 0.88$)$ & $0.72(0.67$ to 0.77$)$ & - \\
\hline Nulliparous & 1.00 & 0.95 (091 to 0.99) & $0.85(0.80$ to 0.90$)$ & $0.83(0.78$ to 0.89$)$ & 0.73 (0.68 to 0.79$)$ & \multirow{2}{*}{0.001} \\
\hline Multiparous & 1.00 & $0.93(0.88$ to 0.97$)$ & $0.79(0.75$ to 0.84$)$ & $0.77(0.72$ to 0.83$)$ & $0.66(0.61$ to 0.71$)$ & \\
\hline \multicolumn{7}{|c|}{ Adjusted relative risk $(95 \% \mathrm{Cl})$ : Model 3} \\
\hline All & 1.00 & $0.96(0.92$ to 1.00$)$ & $0.93(0.89$ to 0.97$)$ & 0.91 (0.87 to 0.95$)$ & $0.87(0.83$ to 0.91$)$ & - \\
\hline Nulliparous* & 1.00 & 0.95 (0.90 to 1.00$)$ & 0.93 (0.88 to 0.97$)$ & $0.90(0.85$ to 0.95$)$ & 0.87 (0.82 to 0.92$)$ & \multirow{2}{*}{0.48} \\
\hline Multiparous* & 1.00 & 0.94 (0.89 to 0.99) & $0.90(0.86$ to 0.95$)$ & 0.92 (0.87 to 0.97$)$ & $0.86(0.81$ to 0.91$)$ & \\
\hline
\end{tabular}

2419 (0.04\%) births had no information on parity; singletons only.

*Model 3 by parity without adjustment for Robson classification. 


\begin{tabular}{|c|c|c|c|c|c|c|}
\hline Variables & 2012 & 2013 & 2014 & 2015 & 2016 & $\begin{array}{l}\text { P value } \\
\text { (interaction) }\end{array}$ \\
\hline \multicolumn{7}{|c|}{ Weighted pregnancy-related mortality rate (per 100000 births) (No of deaths) } \\
\hline All & $7.7(114)$ & $10.5(152)$ & $7.6(125)$ & $6.6(105)$ & $7.1(113)$ & \multirow[t]{3}{*}{-} \\
\hline Nulliparous & $5.1(53)$ & $9.0(84)$ & $7.0(71)$ & $5.3(46)$ & $5.4(49)$ & \\
\hline Multiparous & $12.0(60)$ & $12.9(68)$ & $8.4(53)$ & $8.2(59)$ & $8.7(64)$ & \\
\hline \multicolumn{7}{|c|}{ Crude relative risk $(95 \% \mathrm{Cl}):$ Model 1} \\
\hline All & 1.00 & $1.37(1.02$ to 1.84$)$ & $0.99(0.74$ to 1.32$)$ & $0.86(0.64$ to 1.15$)$ & $0.91(0.64$ to 1.30$)$ & - \\
\hline Nulliparous & 1.00 & 1.76 (1.17 to 2.65$)$ & $1.36(0.90$ to 2.06$)$ & $1.02(0.63$ to 1.64$)$ & 1.05 (0.58 to 1.9$)$ & \multirow{2}{*}{0.45} \\
\hline Multiparous & 1.00 & $1.07(0.74$ to 1.57$)$ & $0.69(0.47$ to 1.02$)$ & $0.68(0.47$ to 1.00$)$ & $0.72(0.49$ to 1.06$)$ & \\
\hline \multicolumn{7}{|c|}{ Adjusted relative risk $(95 \% \mathrm{Cl}):$ Model 3} \\
\hline All & 1.00 & 1.33 (0.98 to 1.82$)$ & $1.00(0.74$ to 1.36$)$ & 0.77 (0.56 to 1.07) & $0.86(0.61$ to 1.23$)$ & - \\
\hline Nulliparous* & 1.00 & $1.68(1.08$ to 2.61$)$ & $1.30(0.83$ to 2.04$)$ & $0.87(0.53$ to 1.44$)$ & $0.94(0.55$ to 1.63$)$ & \multirow{2}{*}{0.64} \\
\hline Multiparous* & 1.00 & 1.07 (0.72 to 1.58$)$ & $0.78(0.52$ to 1.18$)$ & $0.73(0.48$ to 1.12$)$ & $0.81(0.52$ to 1.26$)$ & \\
\hline
\end{tabular}

section rates was most pronounced in hospitals with the highest rates in 2012, consistent with the Chinese government's policy of targeting such hospitals. Perinatal mortality declined from 10.1 to 7.2 per 1000 births over the same period (adjusted relative risk 0.87, 0.83 to 0.91 ), and there was no change in pregnancy related mortality over time.

\section{Comparison with other studies}

The relaxation of the one child policy in November 2013 and the introduction of the two child policy in October $2015^{26}$ has led to more families having a second child. ${ }^{37}$ In our data, the proportion of multiparous births increased from about a third of all births (34.1\%) in 2012 to nearly half of all births $(46.7 \%)$ in 2016. Multiparous births are highly heterogeneous, however, and associated risks varyparticularly whether or not the woman has a uterine scar. While multiparous births without a uterine scar increased from $24.2 \%$ to $28.9 \%$ of all births between 2012 and 2016, the contribution of those with a uterine scar nearly doubled (from $9.8 \%$ to $17.7 \%$ of all births). These proportions are consistent with those found in the World Health Organization facility based surveys in China in 2007-08 and 2010-11. ${ }^{32}$

The caesarean section rates reported here are similar to those described by WHO in 2008 and 2010 in a sample of large hospitals in China, ${ }^{24} 32$ but are higher than the rates obtained from population based sources. The 2009-2011 National Health Service Survey reported a rate of $36.3 \%$ in $2011,{ }^{19}$ and the 2013 National Health Service Survey reported a rate of 40.9\% in 2013 (unpublished), whereas the National Maternal and Child Health Statistics office published a rate of $34.9 \%$ for $2014 .{ }^{8}$ The NMNMSS oversampled large referral hospitals in urban districts, where caesarean section rates were higher than those in smaller hospitals. Weighing the data by the population distribution in urban districts and rural counties in each region accounted for the NMNMSS's oversampling of urban districts, but whether this adjusted fully for the oversampling of large hospitals is not known.

\section{Findings of this study}

China is the only country that has succeeded in reverting the rising trends in caesarean sections..$^{32} 38 \mathrm{In}$ a review of global trends in caesarean sections between 1990 and 2014, one study found only two countriesGuinea and Nigeria-where the caesarean section rate decreased, but these were countries with extremely low caesarean section rates. In countries with excessively high caesarean section rates, such as Brazil and the Dominican Republic, caesarean section rates have grown steadily, to reach $56 \%$ in $2013 .^{38}$ China's

\begin{tabular}{|c|c|c|c|c|c|c|}
\hline Variables & 2012 & 2013 & 2014 & 2015 & 2016 & $\begin{array}{l}\text { P value } \\
\text { (interaction) }\end{array}$ \\
\hline \multicolumn{7}{|c|}{ Weighted rate (per 10000 births) (No of births) } \\
\hline Nulliparous & $1.5(862217)$ & $2.0(816344)$ & $2.2(895213)$ & $2.4(725501)$ & $2.4(802064)$ & \multirow[t]{3}{*}{ - } \\
\hline Multiparous without uterine scar & $2.4(316197)$ & 2.6 (319343) & $3.3(374547)$ & $3.6(362943)$ & $3.1(435009)$ & \\
\hline Multiparous with uterine scar & $28.4(128107)$ & $37.6(139963)$ & $60.2(187792)$ & $81.3(200647)$ & $87.3(265770)$ & \\
\hline \multicolumn{7}{|c|}{ Crude relative risk $(95 \% \mathrm{Cl}):$ Model 1} \\
\hline Nulliparous & 1.00 & $1.34(1.02$ to 1.75$)$ & $1.49(1.01$ to 2.18$)$ & $1.61(1.12$ to 2.30$)$ & $1.62(1.14$ to 2.29$)$ & \multirow{3}{*}{0.00} \\
\hline Multiparous without uterine scar & 1.00 & $1.07(0.74$ to 1.54$)$ & $1.36(0.97$ to 1.90$)$ & 1.49 (1.06 to 2.08$)$ & $1.29(0.92$ to 1.79$)$ & \\
\hline Multiparous with uterine scar & 1.00 & $1.33(1.10$ to 1.59$)$ & $2.12(1.50$ to 3.00$)$ & 2.86 (2.04 to 4.02$)$ & 3.07 (1.98 to 4.78$)$ & \\
\hline \multicolumn{7}{|c|}{ Adjusted relative risk $(95 \% \mathrm{Cl})$ : Model $3^{*}$} \\
\hline Nulliparous & 1.00 & $1.33(1.02$ to 1.74$)$ & $1.47(1.02$ to 2.14$)$ & 1.57 (1.11 to 2.21$)$ & 1.59 (1.14 to 2.22$)$ & \multirow{3}{*}{0.00} \\
\hline Multiparous without uterine scar & 1.00 & 1.06 (0.74 to 1.51$)$ & 1.30 (0.94 to 1.79$)$ & 1.41 (1.01 to 1.95$)$ & $1.20(0.85$ to 1.69$)$ & \\
\hline Multiparous with uterine scar & 1.00 & $1.30(1.09$ to 1.55$)$ & 2.02 (1.44 to 2.83$)$ & $2.60(1.91$ to 3.55$)$ & 2.83 (1.89 to 4.23$)$ & \\
\hline
\end{tabular}

6925 (0.1\%) births had no information on parity and presence of uterine scar.

* Model 3 not adjusted for Robson classification and complications. 
success is even more remarkable, since the decrease in caesarean sections is most pronounced in women less in need of a caesarean section (eg, nulliparous and multiparous singleton cephalic births at term without a uterine scar), while the rates remained unchanged among those clinically needing a caesarean section.

A key question is whether the decline in caesarean section rates is due to the decision by the Chinese government to change its one child policy or to the introduction of policies specifically aimed at reversing the high caesarean section rate. The demographic changes brought about by the one child policy-for example, more women giving birth at older ages or with a uterine scar-would have led to an increase rather than a decline in caesarean section rates. Indeed, adjusting the time trends in caesarean section rates for the changes associated with the one child policy amplified the time trends, suggesting that the downward trend in caesarean section rates happened regardless of the relaxation of the one child policy. Whether the decline in caesarean section rates among nulliparous women can be explained, at least in part, by changes in the assessment of the risk to benefit ratio of a caesarean section now that more women can have another pregnancy, is uncertain. Knowledge that more women can have a subsequent pregnancy, where the risks of a caesarean section are greater, may well lead some clinicians and women to opt for a vaginal delivery in the woman's first pregnancy. However, the greatest decline in caesarean sections was observed among multiparous women without a uterine scar, a group in which the relaxation of the one child policy is unlikely to have had an impact. Most women who are pregnant for the first time may not know whether they want another child, and it is unlikely that changes in the number of children that women are planning to have will change their or their clinician's decision making around the first delivery.

Longer time trends in caesarean section rates may further elucidate the contribution of the relaxation of the one child policy to the decrease in caesarean section rates in China. Three studies have reported on national caesarean section rates over time in China. ${ }^{8}$ ${ }^{15}{ }^{19}$ Feng and colleagues, ${ }^{15}$ using data from four nationally representative surveys between 1993 and 2008, reported increasing rates in urban and rural areas in nulliparous and multiparous women between 1993 and 2008. Meng et al, ${ }^{19}$ using the same survey data for 2003 and 2008 but adding a new nationally representative survey in 2011 reported continually increasing rates in rural areas between 2008 and 2011 (from $25.0 \%$ to $33.3 \%$ ). However, for the first time, the authors reported decreasing caesarean section rates in urban areas (from 53.3\% in 2008 to $46.8 \%$ in 2011). Lastly, Li et al, ${ }^{8}$ using national report data from all counties in China between 2008 and 2014 reported increasing caesarean section rates overall (from $28.8 \%$ to $34.9 \%$ ) but declining rates in large cities and counties that had high rates in 2008. In the largest cities, caesarean section rates declined steadily from $53 \%$ in $2009 / 10$ to $47 \%$ in 2014 ; in areas with high caesarean section rates in 2008 the decline was similar (from $60 \%$ in 2009 to $53 \%$ in 2014). Unfortunately, neither Meng et $\mathrm{al}^{19}$ nor Li et $\mathrm{al}^{8}$ report data by parity, but a comparison of our data with the data from the WHO surveys in 2007/08 and 2010/11 suggests that the decline may have started before 2010/11. ${ }^{32}$ This suggests that caesarean section rates in China started declining a few years before the relaxation of the one child policy.

The timing of the decline in caesarean sections coincides with the Chinese government's explicitly stated concern about the risks associated with caesarean sections and its introduction of several policies to deal with the high caesarean section rates (see appendix table 1). China's approach to reducing caesarean sections has been largely top-down, with national or local government and obstetric societies setting caesarean section targets and introducing financial and other incentives when targets are reached, or penalties when targets are exceeded. The number of caesarean sections without medical indication are now used as an indicator to assess the performance of hospitals, including whether the hospital qualifies as a baby friendly hospital, and caesareans performed for non-medical indications need to be reported to the hospital director for review. ${ }^{25}$ Some hospitals have also taken initiatives themselves, including health education for pregnant women. ${ }^{821}$ In a tertiary centre in Shanghai, for example, the local government set caesarean section targets and introduced a fixed reimbursement rate regardless of mode of delivery. ${ }^{21}$ At the same time the hospital introduced a multifaceted intervention, including antenatal classes informing women about the benefits of vaginal delivery, pain relief for vaginal delivery, and a bonus to individual providers whose caesarean section rates are low. As a result, caesarean sections in the hospital declined from $51 \%$ to $43 \%$ over a four year period. In our study, many hospitals (78\%) reported that a caesarean section target had been set and most (93\%) had clinical guidelines on indications for caesarean sections. The costs of caesarean sections remained much higher than the costs of vaginal deliveries, however, and few hospitals had introduced a fixed reimbursement rate regardless of mode of delivery.

Other measures to support the reduction in caesarean sections include a revision of clinical guidelines for the management of labour, training in the use of forceps and vacuum extraction, and the training and deployment of midwives. First, in 2014, the Association of Gynaecologists and Obstetricians in China issued an "expert consensus on caesarean sections," which gave doctors the right to refuse a caesarean section on request when they deemed it not to be medically indicated. ${ }^{39}$ If women persisted in their request for a caesarean section their case was referred to the head of the obstetric department for review. Second, revisions to clinical guidelines introduced changes to some dystocia related indications for caesarean sections. A prolonged latent phase of labour, previously an indication for caesarean section, 
was removed from the list of indications, and a new definition of arrest of labour, shifting the onset of labour from $3 \mathrm{~cm}$ to $6 \mathrm{~cm}$ dilation, was introduced. ${ }^{40}$ Third, training on the use of the partograph, forceps delivery, and vacuum extraction was reinforced across the country. Fourth, in an effort to reduce the workload of obstetricians, the Chinese government introduced a new training curriculum for midwives in 2012. By 2014, eight regional training centres were providing midwifery training, and most high level referral hospitals now have a cadre of midwives to manage labour and delivery.

Repeat caesarean birth is associated with an increase in the risk of placenta praevia or placenta accreta, infection, damage to the bladder and bowel, deep vein thrombosis, and, on rare occasions, uterine rupture. ${ }^{2728}$ Evidence to date suggests that in women with a uterine scar, a planned caesarean or a planned vaginal birth carries similar risks to the mother and baby, but the evidence is observational and bias cannot be excluded. ${ }^{27}$ In China, repeat caesarean section is the preferred mode of delivery for women with a uterine scar, and opinions on whether more women should undergo a trial of labour vary. ${ }^{41} 42$ Caesarean section rates remained high among women with a uterine scar, and vaginal birth after caesarean section was uncommon. The dramatic increase in the incidence of uterine rupture among women with a uterine scar is potentially worrying, although some of these ruptures may have been a dehiscence with no major clinical consequence. We were unable to investigate the reasons for this increase, but policy makers, clinicians, and researchers across China will need to give urgent attention to how obstetric services cope with the added stress of an increasing number of women with a uterine scar.

Perinatal mortality rates declined over the study period, while pregnancy related mortality remained unchanged, consistent with findings from Beijing, Tianjin, and Zhejiang. ${ }^{8} 4344$ Declining trends in perinatal mortality persisted after adjustment for sociodemographic factors, including parity, suggesting that changes over time in the characteristics of the obstetric population did not explain the findings. We did not examine trends in adverse neonatal outcomes such as birth trauma or respiratory distress, but in a large tertiary hospital in Shanghai the noticeable decline in caesarean sections was not associated with changes in such outcomes, although the frequency of neonatal infection increased slightly. ${ }^{21}$ Caesarean sections remained unchanged among high risk births such as twin or breech deliveries and those with abnormal lie, thereby protecting the most vulnerable infants. In addition, the Chinese government has introduced several strategies that might have contributed to a reduction in perinatal mortality, including a greater number of focused antenatal visits, a system of supervision between tertiary and lower level hospitals, the introduction of neonatal intensive care units in county hospitals, and specific training in neonatal care and resuscitation. ${ }^{34546}$

\section{Strengths and limitations of this study}

The NMNMSS is a well established surveillance system with rigorous quality controls, ${ }^{29} 47$ but data and analytical limitations need to be acknowledged. Firstly, this is not an intervention study and it is not possible to attribute the decline in caesarean sections to one particular policy. However, the timing of the decline and the faster decline in caesarean sections in hospitals with the highest baseline rates are consistent with the government's policy of targeting hospitals with the highest caesarean section rates. By using a statistical model that adjusted for the main demographic and clinical changes potentially associated with the relaxation of the one child policy (including maternal age, Robson classification, maternal complications, and birth weight), we were able to separate the effects of the relaxation of the one child policy from policies specifically aimed at reversing the high caesarean section rate. Secondly, the accuracy of the caesarean section rates over time need careful scrutiny, particularly when the reporting of lower rates can generate positive incentives. The NMNMSS was designed to enumerate maternal deaths and near-miss rather than caesarean sections, however, and those filling out the form for each woman did not know that the mode of delivery would become a focus of investigation. Given that data were collected on individual women, it would have been extremely difficult to manipulate data so that aggregate rates would show declining trends over time. Thirdly, data were only collected in obstetric departments, and babies at high risk of dying who were admitted to a paediatric intensive care unit will have been missed. The early neonatal mortality rate was surprisingly low, although it was consistent with that found in other studies. ${ }^{48}$ While early neonatal mortality rates in the NMNMSS may be biased downward, there is no reason for this to have changed over time. Fourthly, the Robson classification has been recommended as the most appropriate to compare caesarean section rates, ${ }^{32}$

${ }^{49}$ but we were unable to separate women who had spontaneous labour from those who delivered after induction or had a caesarean section before labour, a critical element in understanding caesarean section rates. In the WHO surveys in 2007-08 and 2010-11, caesarean sections fell among single nulliparous births where the labour was induced or the caesarean section was done before labour. ${ }^{32}$ Lastly, the definition of complications relied on the provider's clinical diagnosis, which may be prone to bias. In particular, the ascertainment of uterine rupture in the presence of a scar may be variable. Since the data do not discriminate between an asymptomatic dehiscence that may present at the time of a repeat elective caesarean section and that of uterine rupture which presents as an emergency during labour, the clinical relevance of the findings is uncertain. Although the incidence of uterine rupture reported here among women with a uterine scar is similar to that noted in many other studies, ${ }^{50}$ trends over time have to be interpreted with caution. 


\section{Conclusion and policy implications}

Rigorous evidence of which strategies contribute to reductions in caesarean sections is limited, and interventions that have been shown to work, such as the implementation of guidelines with mandatory second opinion and nurse led preparation classes have resulted in relatively small reductions in caesarean section rates. ${ }^{51-53}$ China's experience suggests that change is possible when strategies address the system level factors that underpin overuse as well as the various incentives at work during a clinical encounter. ${ }^{54}$ As the two child policy gathers momentum in China, and the proportion of births in women with a uterine scar increases further, conditions will have to be created to maintain the safety of repeat caesarean sections, while strategies to avoid medically unnecessary primary caesarean section need to be continually reinforced.

\section{AUTHOR AFFILIATIONS}

${ }^{1}$ National Office for Maternal and Child Health Surveillance of China, Department of Obstetrics, West China Second University Hospital, Sichuan University, Chengdu, Sichuan, China

${ }^{2}$ National Office for Maternal and Child Health Surveillance of China, Department of Pediatrics, West China Second University Hospital, Sichuan University, Chengdu, Sichuan, China

${ }^{3}$ Health, Nutrition and Water, Sanitation \& Hygiene, UNICEF China, Beijing, China

${ }^{4}$ UNICEF Regional Office for South Asia, Kathmandu, Nepal

${ }^{5}$ Key Laboratory of Birth Defects and Related Diseases of Women and Children (Sichuan University), Ministry of Education, Chengdu, Sichuan, China

${ }^{6}$ West China School of Public Health, Sichuan University, Chengdu, Sichuan, China

${ }^{7}$ Department of Infectious Disease Epidemiology, London School of Hygiene \& Tropical Medicine, London, UK

We thank the institutions and staff of the National Maternal Near Miss Surveillance System for data collection.

Contributors: JL and YM are joint first authors. JZ (zhujun028@163. com) and CR contributed equally to the correspondence work. JL, YM, $\mathrm{IZ}$, and CR designed the study with contribution from all authors. YM and WT did the statistical analysis with support from XL and CR. CR wrote the first draft of the paper and all authors contributed to critical interpretation of the results and development of the report. All authors saw and approved the final version. JZ and CR are guarantors.

Funding: This study was supported by the National Health and Family Planning Commission of the People's Republic of China, the National Natural Science Foundation of China (grant No 81330016), the China Medical Board (grant No 11-065), WHO (grant No: CHN-12-MCN-004888), UNICEF (grant No 2016EJH016), and the National "Twelfth Five-Year" Plan for Science and Technology Support (2014BAI06B01)

Competing interests: All authors have completed the ICMJE uniform disclosure form at www.icmje.org/coi_disclosure.pdf (available on request from the corresponding author) and declare: no support from any organisation for the submitted work; no financial relationships with any organisations that might have an interest in the submitted work in the previous three years; no other relationships or activities that could appear to have influenced the submitted work.

Ethical approval: This study was approved by the ethics committee of the West China Second University Hospital (protocol ID, 2012008).

Data sharing: No additional data available.

Transparency: The lead authors (IZ and CR) affirm that the manuscript is an honest, accurate, and transparent account of the study being reported; that no important aspects of the study have been omitted; and that any discrepancies from the study as planned (and, if relevant, registered) have been explained.

This is an Open Access article distributed in accordance with the Creative Commons Attribution Non Commercial (CC BY-NC 4.0) license, which permits others to distribute, remix, adapt, build upon this work non-commercially, and license their derivative works on different terms, provided the original work is properly cited and the use is noncommercial. See: http://creativecommons.org/licenses/by-nc/4.0/.

1 Liang J, Li X, Dai L, et al. The changes in maternal mortality in 1000 counties in mid-Western China by a government-initiated intervention. PLoS One 2012;7:e37458. 10.1371/journal. pone.0037458

2 Cai WW, Marks JS, Chen CH, Zhuang YX, Morris L, Harris JR. Increased cesarean section rates and emerging patterns of health insurance in Shanghai, China. Am J Public Health 1998;88:777-80. 10.2105/ AJPH.88.5.777.

3 Gao Y, Zhou H, Singh NS, et al. Progress and challenges in maternal health in western China: a Countdown to 2015 national case study. Lancet Glob Health 2017;5:e523-36. 10.1016/ S2214-109X(17)30100-6

4 Feng XL, Wang Y, An L, Ronsmans C. Cesarean section in the People's Republic of China: current perspectives. Int I Womens Health 2014;6:59-74. 10.2147/IJWH.S41410.

5 Zhang J, Liu Y, Meikle S, Zheng J, Sun W, Li Z. Cesarean delivery on maternal request in southeast China. Obstet Gynecol 2008;111:1077-82. 10.1097/AOG.0b013e31816e349e.

6 Long Q, Klemetti R, Wang Y, Tao F, Yan H, Hemminki E. High Caesarean section rate in rural China: is it related to health insurance (New Co-operative Medical Scheme)? Soc Sci Med 2012;75:733-7. 10.1016/j.socscimed.2012.03.054

7 Hellerstein S, Feldman S, Duan T. China's 50\% caesarean delivery rate: is it too high? BJOG 2015;122:160-4. 10.1111/1471-0528.12971.

8 Li HT, Luo S, Trasande L, et al. Geographic Variations and Temporal Trends in Cesarean Delivery Rates in China, 2008-2014. JAMA 2017:317:69-76. 10.1001/jama.2016.18663.

9 Blustein J, Liu J. Time to consider the risks of caesarean delivery for long term child health. BMJ 2015;350:h2410. 10.1136/bmj.h2410.

10 Belizán JM, Althabe F, Cafferata ML. Health consequences of the increasing caesarean section rates. Epidemiology 2007;18:485-6. 10.1097/EDE.0b013e318068646a

11 Li H, Ye R, Pei L, Ren A, Zheng X, Liu J. Caesarean delivery, caesarean delivery on maternal request and childhood overweight: a Chinese birth cohort study of 181380 children. Pediatr Obes 2014;9:10-6 10.1111/j.2047-6310.2013.00151.x

12 Xie RH, Lei J, Wang S, Xie H, Walker M, Wen SW. Cesarean section and postpartum depression in a cohort of Chinese women with a high cesarean delivery rate. J Womens Health (Larchmt) 2011;20:1881-6. 10.1089/jwh.2011.2842.

13 Li HT, Ye R, Achenbach TM, et al. Caesarean delivery on maternal request and childhood psychopathology: a retrospective cohort study in China. BJOG 2011;118:42-8. 10.1111/j.1471-0528.2010. 02762.x.

14 Liu X, Landon MB, Cheng W, Chen Y. Cesarean delivery on maternal request in China: what are the risks and benefits? Am J Obstet Gynecol 2015;212:817.e1-9.

15 Feng XL, Xu L, Guo Y, Ronsmans C. Factors influencing rising caesarean section rates in China between 1988 and 2008. Bull World Health Organ 2012;90:30-9, 39A.

16 Hong $X$. Factors related to the high cesarean section rate and their effects on the "price transparency policy" in Beijing, China. Tohoku J Exp Med 2007;212:283-98. 10.1620/tjem.212.283.

$17 \mathrm{Han} \mathrm{H}$ Qin M, Xu HQ et al. The rate of cesarean section and its effect factors in Shanghai[in Chinese]. Maternal and Child Health Care of China 2010;25:3077-80

18 Bogg L, Huang K, Long Q, Shen Y, Hemminki E. Dramatic increase of Cesarean deliveries in the midst of health reforms in rural China. Soc Sci Med 2010;70:1544-9. 10.1016/j.socscimed.2010.01.026.

19 Meng Q, Xu L, Zhang Y, et al. Trends in access to health services and financial protection in China between 2003 and 2011: a cross-sectional study. Lancet 2012;379:805-14. 10.1016/S0140-6736(12)60278-5.

20 Anand S, Fan VY, Zhang J, et al. China's human resources for health: quantity, quality, and distribution. Lancet 2008;372:1774-81. 10.1016/S0140-6736(08)61363-X.

21 Liu X, Lynch CD, Cheng WW, Landon MB. Lowering the high rate of caesarean delivery in China: an experience from Shanghai. BJOG 2016:123:1620-8. 10.1111/1471-0528.14057.

22 Runmei M, Terence T L, Yonghu S, et al. Practice audits to reduce caesareans in a tertiary referral hospital in south-western China. Bull World Health Organ 2012;90:488-94. 10.2471/BLT.11.093369.

23 Ministry of Health of China. Notice of the Ministry of health on Issuing and implementing the implementation plan of the Chinese women and children development program in 2011-2020. 2012. www.nhfpc.gov.cn/fys/s7900/201202/ cffcb29c192d4e529c6290c280507df9.shtml. (in Chinese)

24 Lumbiganon P, Laopaiboon M, Gülmezoglu AM, et al, World Health Organization Global Survey on Maternal and Perinatal Health Research Group. Method of delivery and pregnancy outcomes in Asia: the WHO global survey on maternal and perinatal health 2007-08. Lancet 2010;375:490-9. 10.1016/S0140-6736(09)61870-5. 
25 National Health and Family Planning Commission. Notice on carrying out the review of the baby friendly hospital. 2014. www.moh.gov. cn/fys/s3585/201406/556c0b7673e8470f9641c28d119a9f31. shtml. (in Chinese)

26 Zeng Y, Hesketh T. The effects of China's universal two-child policy. Lancet 2016:388:1930-8. 10.1016/S0140-6736(16)31405-2.

27 Dodd JM, Crowther CA, Huertas E, Guise JM, Horey D. Planned elective repeat caesarean section versus planned vaginal birth for women with a previous caesarean birth. Cochrane Database Syst Rev 2013;(12):CD004224. 10.1002/14651858. CD004224.pub3.

28 Marshall NE, Fu R, Guise JM. Impact of multiple cesarean deliveries on maternal morbidity: a systematic review. Am J Obstet Gynecol 2011;205:262.e1-8.

29 Zhu J, Liang J, Mu Y, et al. Sociodemographic and obstetric characteristics of stillbirths in China: a census of nearly 4 million health facility births between 2012 and 2014 . Lancet Glob Health 2016;4:e109-18. 10.1016/S2214109X(15)00271-5.

30 Ministry of Health of China. The measures for the administration of the hospital grade. 1989. https://baike.baidu.com/item/ \%E5\% 8C\%BB\%E9\%99\%A2\%E5\%88\%86\%E7\%BA\%A7\%E7 \%AE\%A1\%E7\%90\%86\%E5\%8A\%9E\%E6\%B3\%95/420525?fr= aladdin. (in Chinese)

31 Robson M, Hartigan L, Murphy M. Methods of achieving and maintaining an appropriate caesarean section rate. Best Pract Res Clin Obstet Gynaecol 2013;27:297-308. 10.1016/j. bpobgyn.2012.09.004.

32 Vogel JP, Betrán AP, Vindevoghel N, et al, WHO Multi-Country Survey on Maternal and Newborn Health Research Network. Use of the Robson classification to assess caesarean section trends in 21 countries: a secondary analysis of two WHO multicountry surveys. Lancet Glob Health 2015;3:e260-70. 10.1016/ S2214-109X(15)70094-X

33 National Bureau of Statistics of China. National data. http://data. stats.gov.cn/easyquery.htm?cn=E0103. (in Chinese)

34 Li X. Childbirth complications. In: Xie X, Gou WL, eds. Obstetrics and gynecology. 8 ed. Beijing: People's Health Publishing 2013:218. (in Chinese)

35 Zhang WY. Antenatal care. In: Xie X, Gou WL, eds. Obstetrics and gynecology. 8 ed. Bei jing: People’s Health Publishing 2013:142 (in Chinese)

36 Cummings P. Methods for estimating adjusted risk ratios. Stata / 2009;9:175-96

37 National Health and Family Planning Commission. Record of special press conference on 'Comprehensive Two-child' policy progress in Jan, 2017. 2017. www.nhfpc.gov.cn/zhuz/ xwfb/201701/7ea4318bf0f7450aaf91d184e02e5dcf.shtml. (in Chinese)

38 Betrán AP, Ye J, Moller AB, Zhang J, Gülmezoglu AM, Torloni MR. The Increasing Trend in Caesarean Section Rates: Global, Regional and National Estimates: 1990-2014. PLoS One 2016;11:e0148343. 10.1371/journal.pone.0148343.

39 Obstetrics Group of Obstetrics and Gynecological Medical Association, Chinese Medical Association. Expert consensus on caesarean section (2014)[in Chinese]. Chin J Obstet Gynecol 2014:49:721-4.
40 Obstetrics Group of Obstetrics and Gynecological Medical Association, Chinese Medical Association. Expert consensus on new standard and treatment of stage of labour (2014)[in Chinese]. Chin Obstet Gynecol 2014;49:486.

41 Silver RM. VBAC should be encouraged as a means to reduce the caesarean section rate in China: AGAINST: This strategy won't work!BJOG 2016;123(Suppl 3):11. 10.1111/1471-0528.14292.

42 Ma RM, Duan T, Lao TT. VBAC should be encouraged as a means to reduce the caesarean section rate in China: FOR: VBAC reduces not only the caesarean section rate but also other associated issues. BJOG 2016;123(Suppl 3):10. 10.1111/1471-0528.14291.

43 Liu Y, Wang X, Zou L, Ruan Y, Zhang W. An analysis of variations of indications and maternal-fetal prognosis for caesarean section in a tertiary hospital of Beijing: A population-based retrospective cohort study. Medicine (Baltimore) 2017;96:e5509. 10.1097/ MD.0000000000005509.

44 Wu W, Hu L, Qiu L, Qiu L, Hu C. [Analysis of the incidence and perinata outcomes of multiple births in Zhejiang Province from 2008 to 2013] [in Chinese]. Zhonghua Yu Fang Yi Xue Za Zhi 2015;49:265-8.

45 Neonatal Specialized Committee of Chinese Medical Doctor Association. Guidelines for the construction and management of neonatal wards in China (proposal edition)[in Chinese]. Chin J Appl Clin Pediatr 2013:28:231-7.

46 Ministry of Health of China. Neonatal asphyxia resuscitation training program will cover the whole country. 2005. www.nhfpc.gov.cn/ zwgk/jdjd/201304/9fee068b0e2c40e6a3c4584ba9a134cc.shtml. (in Chinese)

47 Huang Y, Tang W, Mu Y, et al. The Sex Ratio at Birth for 5,338,853 Deliveries in China from 2012 to 2015: A Facility-Based Study. PLoS One 2016;11:e0167575. 10.1371/journal.pone.0167575.

48 Lu R, Li X, Guo S, et al. Neonatal mortality in the urban and rural China between 1996 and 2013: a retrospective study. Pediatr Res 2016:79:689-96. 10.1038/pr.2016.6

49 Torloni MR, Betran AP, Souza JP, et al. Classifications for cesarean section: a systematic review. PLoS One 2011;6:e14566. 10.1371/ journal.pone.0014566.

50 Motomura K, Ganchimeg T, Nagata C, et al. Incidence and outcomes of uterine rupture among women with prior caesarean section: WHO Multicountry Survey on Maternal and Newborn Health. Sci Rep 2017:7:44093.10.1038/srep44093.

51 Khunpradit S, Tavender E, Lumbiganon P, Laopaiboon M, Wasiak J, Gruen RL. Non-clinical interventions for reducing unnecessary caesarean section. Cochrane Database Syst Rev 2011;(6):CD005528. 10.1002/14651858.CD005528.pub2.

52 Brown HC, Paranjothy S, Dowswell T, Thomas J. Package of care for active management in labour for reducing caesarean section rates in low-risk women. Cochrane Database Syst Rev 2013;(9):CD004907. 10.1002/14651858.CD004907.pub3.

53 Sandall I, Soltani H, Gates S, Shennan A, Devane D. Midwife-led continuity models versus other models of care for childbearing women. Cochrane Database Syst Rev 2016;4:CD004667. 10.1002/14651858.CD004667.pub5.

54 Elshaug AG, Rosenthal MB, Lavis JN, et al. Levers for addressing medical underuse and overuse: achieving high-value health care. Lancet 2017;390:191-202. 10.1016/S0140-6736(16)32586-7.

Supplementary information: appendix tables 1-4 